\title{
A Interdisciplinaridade nos Estudos de Gênero: análise das teses do Doutorado Interdisciplinar em Ciências Humanas da UFSC
}

\author{
Interdisciplinarity in Gender Studies: analysis of PhD thesis of \\ Interdisciplinary Program on Human Sciences, UFSC
}

\author{
Felipe Bruno Martins Fernandes ${ }^{1}$ \\ Paula Pinhal de Carlos ${ }^{2}$
}

\section{RESUMO}

Este artigo propõe-se a realizar uma análise das teses defendidas na área de concentração de Estudos de Gênero do Doutorado Interdisciplinar em Ciências Humanas da Universidade Federal de Santa Catarina, entre 2003 e 2007. Busca-se, sobretudo, verificar de que maneira a interdisciplinaridade é inserida nessas teses. Além disso, analisa-se quem são os discentes que produziram tais trabalhos, qual é o conteúdo de sua pesquisa de doutoramento, quais são os autores mais utilizados por eles, bem como quem são os docentes que integram essa área do programa de pós-graduação. Dessa forma, é possível concluir que, diferentemente dos professores (que, em sua maioria possuem formação disciplinar), os autores das teses possuem predominantemente uma formação interdisciplinar anterior ao ingresso no curso, sendo privilegiadas, em seus estudos, sobretudo as áreas da Antropologia e da Sociologia.

Palavras-chave: Interdisciplinaridade. Estudos de Gênero. Teses

\section{ABSTRACT}

The purpose of this article is to analyze the thesis defended at the "Programa de Pós-Graduação Interdisciplinar em Ciências Humanas", at the "Universidade Federal de Santa Catarina" (UFSC) on the Gender Studies field, between 2003 and 2007. Our goal is to check on how the interdisciplinary approaches are used in such thesis. In addition, the article examines who are the students who produced these thesis, what is the content of their doctoral thesis, which are the authors most used by them, and who are the teachers within that area of the program. Thus, it was possible to conclude that, unlike the professors, who mostly have disciplinary training, the authors of the thesis have a predominantly interdisciplinary training prior to entering

\footnotetext{
Doutorando interdisciplinar em Ciências Humanas pela Universidade Federal de Santa Catarina. Tem experiência nos Estudos de Gênero e Estudos Gays e Lésbicos, formação de profissionais da educação nas temáticas de gênero e sexualidades. Atua principalmente nos seguintes temas: homofobia, sexualidades, gênero, homossexualidades, direitos humanos e ativismo (social). Tem interesse pelas políticas públicas vinculadas ao programa federal "Brasil Sem Homofobia". complex.lipe@gmail.com

${ }^{2}$ Cursa o Doutorado Interdisciplinar em Ciências Humanas da Universidade Federal de Santa Catarina. É pesquisadora no Núcleo de Identidade de Gênero e Subjetividades da UFSC. Tem experiência nas áreas de Estudos de Gênero e Direito.paulapinhal@hotmail.com
} 
the course, and that the students of this field work mostly with the areas of Anthropology and Sociology.

Keywords: Interdisciplinarity. Gender Studies. Thesis

\section{INTRODUÇÃO}

Este trabalho registra a produção acadêmica do Doutorado Interdisciplinar em Ciências Humanas (DICH), da Universidade Federal de Santa Catarina (UFSC), entre os anos de 2003 e 2007, na área de Estudos de Gênero, totalizando 11 teses defendidas. Nosso objetivo foi o de mapear como a interdisciplinaridade é trabalhada nas teses dessa área. Para tanto, lemos as teses em questão, direcionando o olhar especialmente para a presença da interdisciplinaridade (ou não presença) nos manuscritos e a forma com que essa se dá nos trabalhos. Além disso, pesquisamos a formação dos alunos e professores que orientaram teses e verificamos quais foram os autores mais utilizados.

Salienta-se que os Estudos de Gênero consistem num campo interdisciplinar por excelência. Por esse motivo, os núcleos de pesquisa que atuam nessa área agregam pesquisadores que são oriundos desde as Ciências Humanas e de Letras até áreas como Saúde, Direito e Educação (FONSECA, 1998). Segundo Miriam Pillar Grossi (1998), a década de 1980 vê emergir uma série de pesquisas sobre as mulheres brasileiras, impulsionando a realização de disciplinas específicas sobre a temática em cursos de pós-graduação. Logo, a área de Estudos de Gênero do DICH congrega os dois aspectos acima citados, quais sejam: a interdisciplinaridade da área e a consolidação das pesquisas sobre gênero, mais de duas décadas após sua emergência. Sendo assim, torna-se extremamente relevante a análise das teses do programa de pós-graduação em questão, por serem representativas das pesquisas realizadas na área de Estudos de Gênero no país.

\section{OS DISCENTES E SUAS TESES}

Num primeiro momento, torna-se necessário visualizar quem são os discentes do DICH que defenderam teses de doutorado na área de Estudos de Gênero, perscrutando qual sua formação acadêmica, por exemplo, e qual é a temática do 
seu trabalho. Marlene Tamanini possui graduação em Ciências Sociais e Políticas e mestrado em Sociologia Política. Sua incursão na interdisciplinaridade se deu apenas no $\mathrm{DICH},{ }^{3}$ onde defendeu a tese "Novas tecnologias conceptivas à luz da bioética e das teorias de gênero: casais e médic@s ${ }^{4}$ no sul do Brasil”, orientada por Miriam Pillar Grossi e co-orientada por Luzinete Simões Minella, em 2003.

Miriam Adelman possui graduação em Sociologia e mestrado em Sociologia. Foi apenas no DICH que sua formação passou a ter caráter interdisciplinar, onde defendeu a tese "A voz e a escuta: encontros e desencontros entre a teoria feminista e a sociologia contemporânea", orientada por Miriam Pillar Grossi e co-orientada por Júlia Silvia Guivant, em 2004.

Adriano Henrique Nuernberg possui graduação em Psicologia e mestrado em Psicologia. Sua incursão na interdisciplinaridade também se deu apenas no DICH, onde defendeu a tese intitulada "Gênero no contexto da produção científica brasileira em Psicologia", orientada por Mara Coelho de Souza Lago e co-orientada por Miriam Pillar Grossi, em 2005.

Myriam Aldana Vargas Santin possui graduação em Sociologia e mestrado em Ciências da Religião, momento a partir do qual é possível perceber a interdisciplinaridade em sua trajetória. No $\mathrm{DICH}$ defendeu a tese "Sexualidade e reprodução: da natureza aos direitos: a incidência da Igreja Católica na tramitação do PL 20/91 - aborto legal e PL 1151/95 - união civil entre pessoas do mesmo sexo", orientada por Joana Maria Pedro e co-orientada por Miriam Pillar Grossi, em 2005.

Nádia Terezinha Covolan possui graduação em Filosofia e Enfermagem, é especialista em Pensamento Contemporâneo, em Enfermagem do Trabalho e em Enfermagem e Saúde Pública e possui mestrado em Tecnologia. Sua incursão na interdisciplinaridade se deu já na graduação, já que cursou duas faculdades

\footnotetext{
3 A incursão na interdisciplinaridade de cada doutorando do $\mathrm{DICH}$ foi analisada, aqui, apenas a partir da formação acadêmica. Procuramos verificar se, na sua trajetória, da graduação ao doutorado, verifica-se a presença de áreas do conhecimento diferentes e que tenham sido articuladas na tese de doutorado. Isso não significa que os estudos realizados por essas pessoas não tenham sido interdisciplinares já desde a graduação, sobretudo porque, conforme já explicitado, os estudos de gênero articulam diversas áreas do conhecimento.

A arroba é utilizada no título da tese de Marlene Tamanini, assim como em diversos textos da área de estudos de gênero, como forma de englobar tanto feminino quanto masculino, opondo-se à linguagem corrente, segundo a qual o masculino deve ser utilizado para englobar mulheres e homens.
} 
diferentes e continuou os estudos, na especialização, nessas duas áreas. No DICH defendeu a tese "Corpo vivido e gênero: a menopausa no homoerotismo feminino", orientada por Joana Maria Pedro e co-orientada por Luzinete Simões Minella, em 2005.

Cristina Tavares da Costa Rocha possui graduação em Jornalismo e mestrado em Tecnologia. Foi a partir do mestrado que ela se inseriu na interdisciplinaridade. No DICH defendeu a tese "Gênero em ação: rompendo o teto de vidro?: novos contextos da tecnociência", orientada por Carmen Silvia de Moraes Rial e co-orientada por Luzinete Simões Minella, em 2006.

Luiz Fernando Neves Córdova possui graduação em Psicologia, é especialista em Educação Sexual e em Administração Pública e possui mestrado em Psicologia. Sua incursão na interdisciplinaridade se deu a partir da especialização. No DICH defendeu a tese "Trajetórias de homossexuais na ilha de Santa Catarina: temporalidades e espaços", orientada por Mara Coelho de Souza Lago e coorientada por Sônia Weidner Maluf, em 2006.

Leandro Castro Oltramari possui graduação em Psicologia e mestrado em Psicologia. Foi apenas a partir do doutorado que sua formação interdisciplinar teve início. No DICH defendeu sua tese, intitulada "Representações sociais da AIDS, relações conjugais e confiança”, orientada por Brígido Vizeu Camargo e co-orientada por Miriam Pillar Grossi, em 2007.

Tito Sena possui graduação em Psicologia e Engenharia Civil, é especialista em Psicologia Educacional e Escolar e em Educação Sexual e possui mestrado em Psicologia. A partir da especialização mostrou-se como possuindo formação interdisciplinar, já que seus estudos posteriores não estão ligados ao curso de Engenharia Civil. No DICH defendeu, em 2007, a tese "Os relatórios Kinsey, Masters \& Johnson, Hite: as sexualidades estatísticas em uma perspectiva das ciências humanas", orientada por Mara Coelho de Souza Lago e co-orientada por Miriam Pillar Grossi.

\section{O CORPO DOCENTE}

Em relação aos professores que participaram na orientação e co-orientação das teses analisadas, tem-se que Mara Coelho de Souza Lago orientou três 
trabalhos, sendo seguida, em ordem de preferência dos doutorandos, por Miriam Pillar Grossi e Joana Maria Pedro, cada uma com dois trabalhos. Na co-orientação, Miriam Pillar Grossi foi a mais escolhida, com quatro trabalhos, sendo seguida por Luzinete Simões Minella, com três trabalhos.

Tratando-se de um programa de pós-graduação interdisciplinar, cabe também analisar a formação dos professores que participaram como orientadores e coorientadores das teses aqui investigadas. Mara Coelho de Souza Lago revela-se como a que possui a formação acadêmica mais diversificada, pois sua interdisciplinaridade se dá a partir da especialização. Possui graduação em Pedagogia, é especialista em Planejamento de Recursos Humanos em Santa Catarina e em Ciências Sociais (Antropologia), possui mestrado em Antropologia e doutorado em Educação.

Carmen Silvia de Moraes Rial possui formação interdisciplinar desde a graduação, pois é formada em Comunicação Social (Jornalismo) e em Ciências Sociais, tem mestrado em Sociologia e Antropologia e doutorado e pós-doutorado também em Antropologia. No caso de Sônia Weidner Maluf, a interdisciplinaridade aparece a partir do mestrado, já que possui graduação em Jornalismo, mestrado, doutorado e pós-doutorado em Antropologia. Isso também é verificado na formação de Júlia Silvia Guivant, que possui graduação em Filosofia, especialização em Filosofia Política e mestrado, doutorado e pós-doutorado em Sociologia.

Dentre os professores com formação dentro de uma mesma área do conhecimento, cabe citar Brígido Vizeu Camargo, que da graduação ao doutorado restringe-se à área da Psicologia; Joana Maria Pedro, que possui formação, da graduação ao pós-doutorado, em História; Miriam Pillar Grossi, com graduação em Ciências Sociais e formação, do mestrado ao pós-doutorado, em Antropologia e Luzinete Simões Minella, que possui graduação e mestrado em Ciências Sociais e doutorado e pós-doutorado em Sociologia.

\section{A INTERDISCIPLINARIDADE NOS ESTUDOS DE GÊNERO}

A reflexão interdisciplinar, conforme publicado em Relatório da CAPES (2003), é aquela em que duas ou mais disciplinas convergem, contribuindo dessa forma para a desestabilização de fronteiras científicas através da transferência de 
métodos de uma área para outra, o que possibilita a geração de novos conhecimentos e profissionais com fundamentação sólida e integradora. Nesse sentido, todas as teses produzidas na área de Estudos de Gênero do DICH seguem essa orientação.

Das nove teses analisadas, podemos dividir o corpus em dois grandes grupos, segundo a interdisciplinaridade exercida. O primeiro grupo seria aquele composto de teses que visionaram articular duas disciplinas ou campos do conhecimento. O segundo grupo é composto daquelas teses que buscaram articular várias disciplinas das Ciências Humanas.

Tito Sena, Myriam Aldana Vargas Santin e Luiz Fernando Neves Córdova articularam, em seus trabalhos, mais de três áreas do saber. Tito Sena, em sua "Investigação das características discursivas dos relatórios Kinsey, Masters \& Johnson e Hite" (2007, p.16), coloca a interdisciplinaridade como uma perspectiva. O autor afirma que busca a interdisciplinaridade a partir da desestabilização de sua formação inicial, ocorrida a partir do que nomeia como sendo as "intenções e funções individuais/sociais" da Psicologia.

O autor demarca a área do conhecimento de cada personagem de sua pesquisa, ou seja, dos autores dos relatórios que compõe o objeto de sua pesquisa: Kinsey (biólogo zoólogo), Masters (médico ginecologista), Johnson (psicóloga) e Hite (historiadora). Dessa forma, pontua que tais relatórios foram lidos e usados por mais de uma área do conhecimento como as Ciências Biológicas, Ciências da Saúde e Ciências Humanas. Para a análise de seu objeto, portanto, recorre ao pensamento foucaultiano, abordando em sua tese as áreas da Filosofia, Sociologia, Ciência Política, Antropologia, Psicologia, Geografia e História.

Myriam Aldana Vargas Santin buscou mostrar como a Igreja Católica tem interferido na construção dos direitos sexuais e reprodutivos, em nível mundial, na participação em conferências internacionais, e em nível nacional, a partir da presença marcante na cultura brasileira e da ação direta no Congresso Nacional e nas bases eleitorais dos parlamentares durante os anos 1990. Busca conhecer as estratégias e os expedientes utilizados pela Igreja Católica para influenciar os parlamentares a defender seus pontos doutrinais nos projetos referentes à vida sexual e reprodutiva; identificar e analisar estratégias utilizadas entre atores sociais envolvidos na atribuição de significados aos direitos sexuais e reprodutivos; 
entender o que representa para um Estado laico a convivência de três séculos com a Igreja Católica.

A autora utiliza a categoria gênero e outros eixos de análise, como naturalização, fundamentalismo e contextualização histórica. Perpassa várias áreas do conhecimento, como História, Antropologia e Sociologia, além de ter pontos de conexão em outros campos, como a Filosofia. Complementa, em suas palavras, defendendo que a "interdisciplinaridade é imposta pelo próprio objeto de estudo" (SANTIN, 2005, p.II).

Luiz Fernando Neves Córdova (2006, p.94) buscou "compreender como sujeitos homossexuais de Florianópolis, homens e mulheres de diferentes gerações, vive(ra)m na cidade, em diferentes tempos e espaços, identificando seus modos de vida e processos de sociabilidade". O autor narra em sua tese um acontecimento em que seu objeto de estudo, as homossexualidades, foi questionado pela representação discente como um objeto válido para o campo das Ciências Humanas.

Afirma que, a partir da homofobia experienciada, questionou a validade científica de seu trabalho. Afirma, também, que a teoria disciplinou seu olhar, muito marcado pelo entrelaçamento entre sua vida pessoal e profissional, que deixou de ser um olhar curioso. O autor usou em sua tese o método etnográfico, com entrevistas abertas, articulando ainda Psicologia e um recorte histórico.

Articularam duas áreas do conhecimento ou disciplinas os pesquisadores Marlene Tamanini, Cristina Rocha, Miriam Adelman, Adriano Nuernberg, Leandro Castro Oltramari e Nádia Terezinha Colovan. Marlene Tamanini, por sua vez, realiza uma análise de representações dos médicos que trabalham com tecnologias reprodutivas conceptivas e dos casais heterossexuais que fizeram tratamento para engravidar.

Ela busca verificar as representações de médicos e casais inférteis em relação a: intersecção entre sexo/gênero e reprodução humana; circunscrição da filiação, maternidade e paternidade biológica; diferenças nos modelos de compreensão da natureza e da cultura, e seu entrelaçamento com sexo e gênero em sua relação com o natural e o artificial; aspectos éticos/bioéticos envolvidos na percepção e no significado dos riscos. Foi feita uma análise temática, e não uma análise por entrevista. 
Tamanini ainda direciona o olhar para uma coerência temática entre as entrevistas, o que é coerente com modelos explicativos de representações. A interdisciplinaridade é enunciada na primeira frase do resumo: "esta tese foi desenvolvida a partir de uma perspectiva interdisciplinar, na área das ciências humanas" (TAMANINI, 2003, p.VII). Utiliza contribuições do campo biomédico, mas com uma análise sócio-antropológica. Ela também trabalha com o binômio sexo/gênero e com o gênero e a cultura. Não utiliza um conceito específico de gênero, vai de Margareth Mead a Joan Scott, de Gayle Rubin a Judith Butler, passando por autores brasileiros, como Maria Luiza Heilborn.

Cristina Rocha (2006) realizou uma "análise das relações de gênero e tecnociência, no contexto da produção de softwares da informação e da comunicação, cujas bases assentam-se nas ciências exatas" (ROCHA, 2006, p.XII), refletindo, dessa forma, sobre as desigualdades e os padrões tradicionais de comportamentos de homens e mulheres. A autora busca uma recuperação da trajetória de mulheres que ingressaram no mercado de trabalho da tecnociência, partindo de duas questões: até que ponto elas teriam ultrapassado o "teto de vidro" e em que medida elas estariam engendrando tecnociência e promovendo seu próprio empoderamento.

Fundamenta a interdisciplinaridade dos estudos de gênero em Judith Butler. Realizou dois campos em sua pesquisa. No primeiro, fez uma etnografia da incubadora; no segundo, de empresas não-incubadas, fez visitas e entrevistas. Fez observação participante na administração da incubadora. Recorreu a fontes documentais para obter informações sobre as empresas. Nas entrevistas, priorizou as narrativas das mulheres e entrevistou também homens em cargos de chefia. Fez entrevistas com roteiro semi-estruturado. Fez também entrevista on line, por e-mail.

Miriam Adelman objetivou estudar o encontro entre a teoria feminista e a sociologia contemporânea. A questão central da pesquisa trata das formas pelas quais a contribuição feminista é recebida no campo disciplinar da sociologia. Em seu campo a autora tomou depoimentos e fez observações de teóricas feministas, além de examinar o trabalho de importantes sociólogos da contemporaneidade.

Para ela, o DICH proporcionou a liberdade de poder ir e vir entre os saberes e campos das Ciências Humanas, o que, de certa forma, contrapõe a experiência narrada por Luiz Fernando Neves Córdova. Na tese de Miriam Adelman há um 
tópico na conclusão sobre disciplinaridade, no qual fala da disciplinaridade da sociologia e da interdisciplinaridade da teoria feminista.

Adriano Nuernberg (2005) buscou em sua tese "compreender as características da produção científica de pesquisadoras que protagonizaram a incorporação dos estudos de gênero na psicologia, à luz de uma análise antropológica e psicossocial sobre esse campo" (NUERNBERG, 2005, p.VII). Para a consecução desse objetivo, trabalhou com as áreas de Psicologia e Antropologia.

Leandro Castro Oltramari (2007, p.14) objetivou "compreender a influência das representações sociais da AIDS na prevenção, ou não, dos comportamentos de vulnerabilidade frente ao HIV entre homens e mulheres heterossexuais que vivem relacionamentos conjugais". Para o autor, para a consecução deste objetivo, foi necessária uma reflexão interdisciplinar, sendo o DICH um lugar que possibilita a "intersecção entre disciplinas afins" (idem, p.16).

Articula as disciplinas de Psicologia Social (campo em que o autor afirma ser - lugar de onde fala) e a Antropologia. A Psicologia Social seria a área que apresenta o conceito de representações, que possibilitou que o mesmo construísse uma realidade comum a um conjunto social. A Antropologia contribui na pesquisa através de duas vertentes: o conceito de cultura (fundamentado em Clifford Geertz) e os Estudos de Gênero, que visam, segundo o autor, desnaturalizar as desigualdades entre homens e mulheres. "Penso que a interface dessas duas disciplinas, Psicologia Social e Antropologia, compõe junto ao campo da Saúde Coletiva as principais diretrizes dessa tese" (2007, p.22), afirma o autor.

Nádia Terezinha Colovan investigou o fenômeno da menopausa no homoerotismo feminino. A autora expressou, na primeira página de seu trabalho, que no DICH buscou "os Estudos de Gênero e a possibilidade de refletir interdisciplinarmente", já que as vivências da menopausa em mulheres que se identificam com orientação homoerótica "exige reflexões que imbricam natureza e cultura, em aportes das Ciências Naturais e Humanas" (COLOVAN, 2005, p.1).

Nesse sentido, a autora buscou pensar a menopausa a partir de duas correntes do pensamento, a saber, os discursos biomédicos e os discursos feministas e das teóricas de gênero. Tal distinção emerge a partir do entendimento diferencial do conceito de mulher. Para a biomedicina o olhar é centrado no corpo, ou seja, a mulher é vista como um ser universal. Já nos discursos feministas e das 
teóricas de gênero o olhar é deslocado do corpo, fazendo com que a mulher seja entendida como um ser contextualizado.

Além disso, o fenômeno da menopausa, entendido sob quatro questões norteadoras, deve ser refletido interdisciplinarmente, visto que os fenômenos biológicos (reconhecidamente universais) da parada da mestruação e da cessação da fecundidade implicam em mudanças no corpo a partir desses fenômenos biológicos (variações da saúde e transformações corporais). Colovan (2005, p.1) ainda coloca que a menopausa "é um tema interdisciplinar por excelência, que envolve as ciências naturais e humanas e constitui vários discursos, no tempo e no espaço".

\title{
5. A POLÍTICA DE CITAÇÃO
}

Conforme aponta Cláudia Lima Costa (2003), a análise da política de citações é ferramenta útil para se entender a "rede de influências discursivas" que informam o campo dos Estudos de Gênero. Para a autora:

\begin{abstract}
textos (carregando consigo certas marcas epistemológicas) não viajam sem 'visto', eles tampouco viajam 'desacompanhados'. Geralmente seus deslocamentos seguem os rastros dos movimentos mais amplos de outros textos, de problemáticas (por meio, por exemplo, de movimentos sociais) e do capital cultural (por meio de uma elite acadêmica que viaja constantemente ao longo do eixo Norte-Sul e vice-versa) (COSTA, 2003, p.256).
\end{abstract}

Buscando perceber quais textos atuam mais fortemente no $\mathrm{DICH}$, na área referida, a partir de nosso conhecimento do campo, mapeamos textos com maior recorrência nas teses publicadas no período estudado. Em um primeiro momento assinalamos que um mesmo autor era citado em diferentes teses. Além disso, assinalamos também os professores da área de Estudos de Gênero citados, mesmo aqueles com um único trabalho citado. Em um segundo momento, agrupamos todos os autores citados e separamos aqueles que foram visualizados em mais de uma tese. A partir daí, pudemos assinalar aqueles autores que informam mais correntemente as teses do programa e aqueles professores que, de certa maneira, influenciam a produção de conhecimento no programa. 
O filósofo francês Michel Foucault foi o autor com maior recorrência nas teses do programa, tendo tido no mínimo três e no máximo trinta e cinco de seus textos citados. A obra História da Sexualidade 1: a vontade de saber mostrou-se tão recorrente que pode ser avaliada como um clássico do campo dos Estudos de Gênero, pois assume na contemporaneidade um papel crucial na sua produção. Michel Foucault, ao abordar a sexualidade como uma invenção histórica e descentrar o conceito de poder (1979; 2006), abriu novas possibilidades de análise e fundamentou uma série de produções que investem em análises discursivas que buscam desconstruir categorias hegemônicas que nomeiam e normatizam o gênero e as sexualidades.

Nesse mesmo sentido, a filósofa americana Judith Butler, segunda autora com maior recorrência na produção da área, atua na desconstrução do gênero enquanto baseado no sexo, trazendo em sua teoria a noção de performance de gênero. Em seu texto $A$ vida psíquica do poder (1997), por exemplo, a autora recupera o discurso de Foucault e, com base de John Langshaw Austin, afirma que, quando se nomeia, se institui. Como Foucault, a autora parte do pressuposto que os discursos produzem subjetividades. Apesar de se apropriar do pensamento foucaultiano, a autora o critica, afirmando que o filósofo não mostra os mecanismos envolvidos no processo de assujeitamento. Além disso, a partir do pensamento da autora, somos levados a pensar que é preciso desconstruir o lugar estanque dos gêneros em que eles são aparentemente normais.

Maria Luiz Heilborn também foi muito citada pelos doutorandos. A pesquisadora, pertencente ao Centro Latino-americano em Sexualidade e Direitos Humanos (CLAM/IMS/UERJ), trabalha no conjunto de sua obra com um conceito estruturalista de gênero. Anthony Giddens, sociólogo inglês que aparece como quarto autor que mais fundamenta o campo, faz um retrospecto histórico acerca do amor e da sexualidade, dos gregos ao início do século $\mathrm{XX}$, trabalhando com noções de gênero e sexualidade no livro A Transformação da Intimidade, de 1992.

A partir desse ponto, serão apresentados autores com recorrência média nas teses. Michel Bozon é sociólogo e diretor de pesquisa no Institut National d'Études Demographiques em Paris. Suas pesquisas tratam, sobretudo, do tema da sociologia da sexualidade, a partir de enquetes realizadas na França (BAJOS; BOZON, 2008) e no Brasil (HEILBORN et al., 2006), e das questões de gênero. 
John Gagnon é sociólogo norte-americano, baseado no interacionismo simbolico, o autor trabalha com a noção de sexualidade construída, pois trata da determinação sócio-cultural de toda conduta sexual humana. Em parceria com William Simon é responsavel pelo desenvolvimento do conceito de scripts sexuais (GAGNON; SIMON, 1973).

Jurandir Freire Costa é um psicanalista conhecido pelos estudos relacionados à violência praticada contra minorias e às identidades homoeróticas. Richard Parker, por sua vez, é um pesquisador que estuda sexualidades, saúde coletiva e HIVIAIDS. Ambos vinculam-se à área da saúde.

Gayle Rubin, outra autora muito citada, é a criadora, com seu livro O tráfico das mulheres, do sistema sexo-gênero. Já Guacira Lopes Louro trabalha com gênero e educação a partir de uma perspectiva pós-estruturalista, na qual também se insere Jane Flax, que pensa a psicanálise como pós-estruturalista, porque ela fragmenta o sujeito.

Dentre os professores da área de Estudos de Gênero do programa, sobressaiu-se a docente Miriam Pillar Grossi, citada por quase todos os doutorandos. Uma primeira hipótese que levantamos é que a professora teve grande participação como orientadora ou co-orientadora das teses. No entanto, uma de suas orientandas, Miriam Adelman, não a cita. Dessa forma, podemos visualizar a importância teórica dessa professora para o campo dos estudos de gênero no país. Ademais, como parte de uma elite intelectual que circula por outros países, Miriam Pillar Grossi revela-se como alguém que articula a participação de autores estrangeiros em eventos no país, como o que ocorreu com a vinda de Sherry Ortner, na reunião da Associação Brasileira de Antropologia, em 2006 bem como está envolvida na publicação de importantes obras internacionais no Brasil, tais como $A$ cidadã paradoxal, de Joan Scott, na qual atua no prefácio. Além dessa professora, também foram citadas em ordem, Sônia Maluf, Mara Lago e, com importância semelhante, as professoras Carmen Rial, Joana Maria Pedro e Luzinete Minella.

\section{NOTAS CONCLUSIVAS}

A partir da análise das teses da área de Estudos de Gênero do DICH, percebemos que a maioria dos alunos começa a circular na interdisciplinaridade 
anteriormente ao doutorado, o que demonstra que o programa atrai um público que já realizou incursões interdisciplinares. Já os docentes, em maioria, possuem aderência disciplinar, o que pode ser verificado a partir de sua formação acadêmica, muito relacionada a apenas uma área do conhecimento.

Em relação às teses, estas articularam duas ou mais áreas do conhecimento, havendo uma predominância da Antropologia e da Sociologia como campos com os quais quase todos os doutorandos dialogaram. Seriam a Antropologia e a Sociologia espaços propícios para exercícios interdisciplinares? No que tange à política de citação, Michel Foucault e Judith Butler são teóricos que fundamentam a produção de conhecimento no campo dos estudos de gênero, sendo largamente utilizados nas teses analisadas.

Dessa forma, concluímos que os estudos de gênero consistem num campo interdisciplinar por excelência, em que pesquisadores com diferentes formações encontram um locus privilegiado de produção do conhecimento, no que se refere a mulheres, teoria feminista, homossexualidades, sexualidade, direitos sexuais e reprodutivos etc. 


\section{REFERÊNCIAS}

ADELMAN, M. A voz e a escuta: encontros e desencontros entre a teoria feminista e a sociologia contemporânea. Tese (doutorado) - Universidade Federal de Santa Catarina, Programa de Pós-Graduação Interdisciplinar em Ciências Humanas, 2004.

BUTLER, J. The psychic life of power. California: Stanford University Press, 1997.

CÓRDOVA, L. F. N. Trajetórias de homossexuais na ilha de Santa Catarina: temporalidade e espaços. Tese (doutorado) - Universidade Federal de Santa Catarina, Programa de Pós-Graduação Interdisciplinar em Ciências Humanas, 2006.

COSTA, C. L. As publicações feministas e a política transnacional da tradução: reflexões do campo. Estudos Feministas, v. 11, n. 1, p. 254-264, jan./jun. 2003.

COVOLAN, N. T. Corpo vivido e gênero: a menopausa no homoerotismo feminino. Tese (doutorado) - Universidade Federal de Santa Catarina, Programa de PósGraduação Interdisciplinar em Ciências Humanas, 2005.

FONSECA, C. Prefácio. In: PEDRO, J. M.; GROSSI, M. P. Masculino, feminino, plural: gênero na interdisciplinaridade. Florianópolis: Mulheres, 1998.

FOUCAULT, M. Microfísica do poder. Rio de Janeiro: Graal, 1979.

FOUCAULT, M. História da sexualidade 1: a vontade de saber. São Paulo: Graal, 2006.

GAGNON, J. ; SIMON, W. Sexual conduct: the social sources of human sexuality. New Jersey: Rutgers, 1973.

GIDDENS, A. A transformação da intimidade: sexualidade, amor e erotismo nas sociedades modernas. São Paulo: Unesp, 1993.

GROSSI, M. P. Rimando amor e dor: reflexões sobre a violência. In: PEDRO, J. M.; GROSSI, M. P. (orgs). Masculino, feminino e plural: gênero na interdisciplinaridade. Florianópolis: Ed. Mulheres, 1998.

NUERNBERG, A. H. Gênero no contexto da produção científica brasileira em psicologia. Tese (doutorado) - Universidade Federal de Santa Catarina, Programa de Pós-Graduação Interdisciplinar em Ciências Humanas, 2005.

OLTRAMARI, L. C.. Representações sociais da aids, relações conjugais e confiança. Tese (doutorado) - Universidade Federal de Santa Catarina, Programa de Pós-Graduação Interdisciplinar em Ciências Humanas, 2007. 
ROCHA, C. T. C. Gênero em ação: rompendo o teto de vidro? Novos contextos da tecnociência. Tese (doutorado) - Universidade Federal de Santa Catarina, Programa de Pós-Graduação Interdisciplinar em Ciências Humanas, 2006.

SANTIN, M. A. V. Sexualidade e reprodução: da natureza aos direitos: a incidência da Igreja Católica na tramitação do Projeto de Lei 20/91 - aborto legal e Projeto de Lei 1151/95 - união civil entre pessoas do mesmo sexo. Tese (doutorado) Universidade Federal de Santa Catarina, Programa de Pós-Graduação Interdisciplinar em Ciências Humanas, 2005.

SENA, T. Os relatórios Kinsey, Masters \& Johnson, Hite: as sexualidades estatísticas em uma perspectiva das ciências humanas. Tese (doutorado) Universidade Federal de Santa Catarina, Programa de Pós-Graduação Interdisciplinar em Ciências Humanas, 2007.

TAMANINI, M. Novas tecnologias reprodutivas conceptivas à luz da bioética e das teorias de gênero: casais e médicos no sul do Brasil. Tese (doutorado) Universidade Federal de Santa Catarina, Programa de Pós-Graduação Interdisciplinar em Ciências Humanas, 2003.

Artigo:

Recebido em: 08/10/2009

Aceito em: 09/11/2009 